\title{
Semi-active suspension control for formula SAE car using magneto-rheological fluid
}

\begin{abstract}
The Magneto-rheological (MR) fluid damper is prevalent in the field of semi-active suspension whose viscosity changes by the change of magnetic field passing through the damping fluid. In this study, a semi-active suspension quarter car model is employed as a plant. The Bingham model of MRF damper is exploited with PID and Fuzzy + PID controllers. The current is controlled by the controllers according to the quarter car chassis disturbance. The step road profile is used as an input disturbance to the suspension system. The displacement of sprung mass is analyzed in terms of time and frequency domain. The maximum power spectral density of acceleration for step response with Fuzzy + PID is reduced by $87.28 \%$ as compared to passive suspension whereas PID reduced only $79.95 \%$. This indicates that the MRF damper with right tuned Fuzzy + PID controller provide a safer ride compared to PID controller and passive suspension.
\end{abstract}

Keyword: Fuzzy logic; Magneto-rheological fluid damper; PID controller; Semi-active suspension 